\title{
Reduction of Prescription Errors in Neonatal Intensive Care Unit: A Quality Improvement Initiative
}

\author{
Rajat Grover $^{1} \cdot$ Shantanu Shubham $^{1} \cdot$ Jaya Upadhyay ${ }^{1} \cdot$ Kanhu Charan Digal $^{1} \cdot$ Poonam Singh $^{1} \cdot$ Sriparna Basu $^{1}$ (D)
}

Received: 21 April 2020 / Accepted: 4 August 2020 / Published online: 11 August 2020

(C) Dr. K C Chaudhuri Foundation 2020

To the Editor: Prescription is an important component of medication administration. Errors in prescription-writing, an indisputable source of medication errors $[1,2]$, may prove fatal for vulnerable neonates $[3,4]$. This Quality Initiative (QI) project, conceptualised on Point-of-Care Quality Improvement model [5], was prompted by an incidence of under-dosing for not accounting the extra drug volume needed to flush the extension-line in prescription. We aimed to improve the proportion of correct prescriptions from the existing $65 \%$ to $100 \%$ over 6 mo (July-December 2019) in neonates receiving treatment in our neonatal unit.

A QI team was constituted and baseline data were collected over 4 wk (01.07.2019-01.08.2019). The proportions of correct prescriptions and printed prescriptions were taken as outcome and process measures, respectively. The correctness and completeness of prescriptions were determined by an indigenously devised checklist. All prescriptions were prospectively assessed every fourth-day by the designated team member with calculation of process and outcome measures. Baseline data analysed using fishbone diagram and Pareto chart revealed that illegible handwriting, inability to remember components of a prescription and failure to account the extra volume for extension lines were the $20 \%$ causes that determined $70 \%$ of prescription errors.

During the intervention-phase of 16 wk (02.08.201921.11.2019), 8554 components of 611 prescriptions were assessed for correctness. Plan-Do-Study-Act (PDSA) cycle-1 (02.08.2019-29.08.2019) involved training of residents regarding the uniform use of printed prescriptions and a single reference source for drug dosage (IBM $®$ Micromedex ${ }^{\circledR}$

Sriparna Basu

drsriparnabasu@rediffmail.com

1 Department of Neonatology, All India Institute of Medical Sciences, Rishikesh, Uttarakhand 249203, India
Neofax ${ }^{\circledR}$ manual). PDSA-2 (30.08.2019-26.09.2019) involved the development and use of a preformatted prescription template. In PDSA-3 (27.09.2019-24.10.2019), a decision to use only $100 \mathrm{~cm}$ extension lines and addition of this order to the prescription template was made. PDSA-4 (25.10.2019-21.11.2019) involved two-person verification of each prescription. At the end of four sequential PDSA cycles, the proportion of correct prescriptions improved from $65 \%$ to $76.2 \%, 80 \%, 95.8 \%$ and $100 \%$, respectively, and the proportions of printed prescriptions improved from $0 \%$ to $77.3 \%, 95 \%, 96 \%$ and $100 \%$, respectively. During the sustenance-phase (22.11.2019-31.12.2019), 3612 components of 258 prescriptions were checked for correctness. Both the process and outcome measures remained $100 \%$ all throughout.

In this QI initiative, the use of simple, locally-devised problem-oriented PDSA ramps resulted in complete elimination of prescription errors.

\section{Compliance with Ethical Standards}

Conflict of Interest None.

\section{References}

1. Aronson JK. Medication errors: definitions and classification. Br J Clin Pharmacol. 2009;67:599-604.

2. Simpson JH, Lynch R, Grant J, Alroomi L. Reducing medication errors in the neonatal intensive care unit. Arch Dis Child Fetal Neonatal Ed. 2004;89:F480-2.

3. Samra HA, McGrath JM, Rollins W. Patient safety in the NICU: a comprehensive review. J Perinat Neonatal Nurs. 2011;25:123-32.

4. Chappell K, Newman C. Potential tenfold drug overdoses on a neonatal unit. Arch Dis Child Fetal Neonatal Ed. 2004;89:F483-4.

5. POCQI-Learner-Manual.pdf. Available at: https://www. newbornwhocc.org/POCQI-Learner-Manual.pdf. Accessed 15th June 2019.

Publisher's Note Springer Nature remains neutral with regard to jurisdictional claims in published maps and institutional affiliations. 